Article

\title{
Extended Intake of Mulberry Leaf Extract Delayed Metformin Elimination via Inhibiting the Organic Cation Transporter 2
}

\author{
Hyun Wook Huh ${ }^{1,+}$, Young-Guk Na ${ }^{1,+} \mathbb{C}$, Ki-Hyun Bang ${ }^{1}$, Sung-Jin Kim ${ }^{1}$, Minki Kim ${ }^{1}$, \\ Kyung-Tae Kim ${ }^{2}$, Jong-Seong Kang ${ }^{1}$, Young-Ho Kim ${ }^{1}{ }^{(}{ }^{\text {, Jong-Suep Baek }}{ }^{3}{ }^{\mathbb{D}}$, Hong-Ki Lee ${ }^{1, *(\mathbb{D})}$ \\ and Cheong-Weon Cho ${ }^{1, *(1)}$ \\ 1 College of Pharmacy, Chungnam National University, Daejeon 34134, Korea; hhw3573@nate.com (H.W.H.); \\ youngguk@cnu.ac.kr (Y.-G.N.); robotkr@nate.com (K.-H.B.); lanop@naver.com (S.-J.K.); \\ zkzkang@naver.com (M.K.); kangjss@cnu.ac.kr (J.-S.K.); yhk@cnu.ac.kr (Y.-H.K.) \\ 2 Food Science and Technology Major, Division of Applied Bioengineering, College of Engineering, \\ Dong-Eui University, Busan 47340, Korea; kimkkt@deu.ac.kr \\ 3 Department of Herbal Medicine Resource, Kangwon National University, Samcheok 25949, Korea; \\ jsbaek@kangwon.ac.kr \\ * Correspondence: dvmlhk@gmail.com (H.-K.L.); chocw@cnu.ac.kr (C.-W.C.); \\ Tel.: +82-42-821-7301 (H.-K.L.); +82-42-821-5934 (C.-W.C.); Fax: +82-42-823-6566 (H.-K.L. \& C.-W.C.) \\ + These authors contributed equally to the study.
}

Received: 20 November 2019; Accepted: 6 January 2020; Published: 7 January 2020

\begin{abstract}
Diabetes mellitus (DM) has become a major health problem in most countries of the world. DM causes many complications, including hyperglycemia, diabetic ketoacidosis, and death. In Asia, mulberry has been used widely in the treatment of DM. Combination of drugs with herbal medicine may reduce the unwanted side effects caused by drugs. In this study, the influence of extended mulberry leaves extract (MLE) intake on metformin (Met) was evaluated in terms of pharmacokinetics and pharmacodynamics in DM-induced rats. Three week-treatment of MLE alone produced the anti-hyperglycemic effect (around 24\%) if compared to the control. Interestingly, Met administration after MLE treatment for 3 weeks enhanced about $49 \%$ of the anti-hyperglycemic effect of Met. In addition, the extended intake of MLE potentiated the anti-hyperglycemic effect of Met on various concentrations. This potentiated anti-hyperglycemic effect of Met appears to be due to the pharmacokinetic change of Met. In this study, 3 week-treatment of MLE reduced the elimination of Met in DM-induced rats. In addition, MLE reduced the human organic cation transporter 2 (hOCT2) activity in a concentration-dependent manner. Thus, these findings suggest that MLE lowered the elimination of Met via inhibiting the hOCT2.
\end{abstract}

Keywords: diabetes mellitus; metformin;Morus alba L.; mulberry; pharmacokinetics; pharmacodynamics; organic cation transporter 2

\section{Introduction}

Diabetes mellitus (DM) is a major health problem in most countries of the world. According to the World Health Organization (WHO) [1], 422 million peoples are diagnosed as DM, and DM caused 1.5 million death in 2012. DM is characterized by metabolic abnormalities along with symptoms, including hyperglycemia, diabetic ketoacidosis, polyuria, polydipsia, polyphagia, and loss of pancreatic $\beta$-cells [2]. In particular, hyperglycemia can cause severe damage to the blood vessels, which leads to cardiovascular disorders, hepatopathy, nephropathy, and neuropathy [3]. 
Five classes of anti-hyperglycemic drugs-including sulfonylurea, biguanides, $\alpha$-glucosidase inhibitor, meglitinides, and thiazolidinediones-are available for the treatment of DM [4]. Metformin (Met) is a biguanide anti-hyperglycemic drug and is the front-line drug in the management of diabetes in patients. Met reduces blood glucose levels by decreasing glucose output from the liver and by increasing peripheral insulin receptor sensitivity without affecting insulin secretion [5]. However, an endocrine disorder, such as DM, that requires the extended treatment can produce unwanted side effects, including weight gain, liver, and kidney dysfunctions during the extended treatment. Thus, a new approach is needed to decrease the side effects of drugs. The combination therapy is a common approach to enhance the efficacy of the drug and to reduce the unwanted side effects for DM control.

Plants have been used as a therapeutic purpose in many Asian countries, and many drugs are derived from plants. Mulberry, Morus alba L., is the common deciduous tree in Asia. Its products, such as fruits, leaves, and roots have been used traditionally as an anti-hyperglycemic folk remedy in the Asian country. Anti-hyperglycemic effects of mulberry have been frequently reported in literatures [1,6-10]. Although the mechanisms of anti-hyperglycemic actions of mulberry have been less well understood, it has been known that the anti-hyperglycemic effects are related with ingredients, such as caffeic acid, syringaldehyde, chlorogenic acid, and rutin of mulberry [11-17].

Combinations of drugs with herbal medicine may reduce the unwanted side effects caused by drugs. For instance, cinnamic acid derivatives when combined with Met reduced the expression of fatty acid synthase and $\beta$-Hydroxy $\beta$-methylglutaryl-CoA (HMG CoA) reductase involved in the secondary complications of DM $[18,19]$. However, these combinations may produce three different types of effects - namely synergistic, additive, and antagonistic [5]. In addition, it is reported that drug interactions with herbal medicines showed various behaviors [20-23]. In particular, the pharmacokinetic herb-drug interactions related to drug absorption, distribution, metabolism, and elimination, lead to increased or decreased plasma levels of drugs and affect drug efficacy [20-23]. For examples, Hypoxis hemerocallidea and L-canavanine inhibited the P-glycoprotein (P-gp) efflux of nevirapine in the Caco-2 cell [24]. Capsaicin inhibited the P-gp activity in KB-C2 cell and had the potential to induce P-gP in human $[25,26]$. While the St John's wort lowered the disposition of sulfonylureas by induction of various hepatic CYP enzymes, the Cassia inhibited the activities of various hepatic CYP enzyme which metabolize the anti-hyperglycemic drugs, such as glibenclamide, glimepiride, glipizide, and nateglinide $[27,28]$. Moreover, herbal medicines can alter renal drug elimination. It was reported that Houttuynia cordata ethanol extract reduced renal excretion of Met via decrease of organic cation transporters (OCT) uptake of Met [23]. Thus, before applying a combination with herbal medicine, it is critical to evaluate the pharmacokinetic and pharmacodynamic profiles of the drug co-administered with herbal medicine. This study aims to evaluate the influence of extended Morus alba L. extract intake on Met in terms of pharmacokinetics and pharmacodynamics in DM-induced rats.

\section{Materials and Methods}

\subsection{Chemicals and Plant Materials}

Streptozotocin (STZ, purity $\geq 98 \%$ ) and phenformin (internal standard, IS, purity $\geq 98 \%$ ) were purchased from Sigma-Aldrich (St. Louis, MO, USA). Met (purity $\geq 98 \%$ ) was a gift from the Korea United Pharm Inc. (Seoul, Korea). High-performance liquid chromatography (HPLC) grade acetonitrile (ACN) and methanol (MeOH) were purchased from JT baker (Phillipsburg, NJ, USA). All the other agents were of analytical grade and were obtained by commercial sources. The mulberry leaf extracts (MLE) were obtained from the MSC (Yangsan, Korea). Briefly, Morus alba L. was added into purified water and then extracted under the pressure at $121^{\circ} \mathrm{C}$ for $3 \mathrm{~h}$. These extracts were fermented by adding $1 \%(w / v)$ enzyme (Viscozyme ${ }^{\circledR}$ ) under $\mathrm{pH} 5.0$ at $45^{\circ} \mathrm{C}$ for $15 \mathrm{~h}$. MLE was dried using a freeze-dryer [29]. MLE used in this study included phytochemicals such as trans-caffeic acid, syringaldehyde and chlorogenic acid that have been known to increase glucose uptake into skeletal muscle cells. In MLE, trans-caffeic acid was the substance with the highest content (about $0.7 \mathrm{mg} / \mathrm{g}$ ). 


\subsection{Animals}

Male Sprague-Dawley rats were used in this study. Rats aged 7 weeks were obtained by Samtako (Osan, Korea), and they were housed at $22{ }^{\circ} \mathrm{C}$ with a 12-h light-dark cycle and given free access to food and water. Before the experiments, animals were acclimated for 1 week. All experiments were performed according to the guidelines established by the Chungnam National University Institutional Animal Care and Use Committee. This study was approved by the Local Ethical Committee of Chungnam National University (protocol no. CNU-01150, 19 October 2018).

\subsection{Induction of DM}

DM was induced by an injection of STZ. Animals were fasted overnight and then STZ was injected via tail vein at a dose of $45 \mathrm{mg} / \mathrm{kg}$. To overcome the acute hypoglycemia, $5 \%$ glucose solution was provided a day. Animals were fasted at least $8 \mathrm{~h}$ before collecting whole blood via jugular vein, and then fasting blood glucose level was measured using a blood glucose meter (Accu-Chek ${ }^{\circledR}$ Active, Hoffmann-La Roche, Basel, Switzerland). Glucose level was measured at 0, 1, and 5 days post-injection of STZ. Fasting glucose level above $200 \mathrm{mg} / \mathrm{dL}$ was set as the criteria of DM.

\subsection{Anti-Hyperglycemic Effect of Repeated Administrations of MLE}

To evaluate the anti-hyperglycemic effect of repeated administrations of MLE, MLE was orally administered at a single dose of $600 \mathrm{mg} / \mathrm{kg}$ for 21 days. As a negative control, saline was administered for 21 days. The dose of MLE was selected by the preliminary study. According to the literature [30], the dosage of MLE at a single dose of $600 \mathrm{mg} / \mathrm{kg} /$ day for 49 days was produced the antidiabetic effect and well-tolerated in animals. Blood samples were collected on $0,2,4,6,9,12,15,18,21,22$ days and the fasting glucose levels were measured. Fasting glucose level was converted to the relative blood glucose level by a following Equation (1)

$$
\text { Relative blood glucose level }=\frac{\text { Fasting blood glucose level at time points }}{\text { Fasting blood glucose level at } 0 \mathrm{~h}} \times 100(\%)
$$

Anti-hyperglycemic effect was estimated using an area under curves of the relative blood glucose level versus time curves (AUG). AUG was calculated by a trapezoidal rule.

\subsection{Impact of Repeated Administrations of MLE on the Anti-Hyperglycemic Effect of Various Doses of Met}

To evaluate the influence of repeated administrations of MLE on the anti-hyperglycemic effect of various doses of Met, the MLE was orally administered for 21 days and then the increasing doses of Met were orally administered on day 22. Briefly, animals orally received saline or MLE (600 mg/kg) of the same volume for 21 days. On day 22, animals received the increasing doses of Met (25, 50, and $100 \mathrm{mg} / \mathrm{kg}$ ). Fasting glucose level was measured at 0, 2, 4, and $12 \mathrm{~h}$ post-administration of Met. AUG was calculated as described in Section 2.4. The AUG value corresponding to each dose of MET was analyzed by linear regression and the slope was evaluated. Statistical differences of slope between MLE and saline treatment group was assessed by the Student's $t$-test.

\subsection{Influence of Repeated Administrations of MLE to the Pharmacokinetics of Met}

Pharmacokinetic interaction between herb and drug has been reported in many studies. To evaluate the interaction between the MLE and Met, pharmacokinetic analysis of Met was assessed after the repeated administrations of MLE or saline. Briefly, MLE (600 mg/kg, PO, orally once a day) or saline was orally administered to animals for 21 days, then the animal received the Met per oral at a dose of $50 \mathrm{mg} / \mathrm{kg}$. After the administration of Met, the blood samples were taken via jugular vein at $0.5,1,1.5,2,4,6,8,12$, and $24 \mathrm{~h}$. Blood samples were centrifuged at $1000 \times g$ for 10 min and the plasma was stored at $-70^{\circ} \mathrm{C}$. The plasma samples were analyzed by HPLC with a UV detector. PK 
parameters for oral administration were determined as a non-compartmental model using WinNonlin 5.3.1 software (Pharsight, Princeton, NJ, USA).

\subsection{Interference of MLE to Met Analysis in Rat Plasma}

To evaluate the interfering effect of MLE presence to Met analysis in rat plasma, the Met-spiked samples with the MLE $(10 \mu \mathrm{g} / \mathrm{mL})$ in rat plasma were used and the validation parameters such as accuracy and precision were evaluated in the presence or absence of MLE in rat plasma.

For the calibration curve, the peak area ratios of Met $(0.2,0.4,0.8,1,2.5,5$, and $10 \mu \mathrm{g} / \mathrm{mL})$ to IS were plotted against corresponding nominal concentrations of Met. The linearity of the regression curve in the range $0.4-10 \mu \mathrm{g} / \mathrm{mL}$ was assessed on the base of the residual plot. Concentrations of the samples were interpolated from the regression curve. The correlation coefficient of the calibration curve was $>0.99$.

Inter- and intra-day reproducibility was measured to assess accuracy and precision using quality control (QC) samples (low QC, LQC, $0.5 \mu \mathrm{g} / \mathrm{mL}$; medium QC, MQC, $1 \mu \mathrm{g} / \mathrm{mL}$; high QC, HQC, $5 \mu \mathrm{g} / \mathrm{mL}$ ). The relative error (RE) and relative standard deviation (RSD) were used to evaluate the accuracy and precision of the bioanalytical method. The $\pm 15 \%$ fixed range applied as an acceptance of criteria.

In addition, to assess the interference in the chromatogram from the MLE at the retention time of Met, the chromatogram of plasma samples obtained from rats received the MLE for 21 days was analyzed.

\subsection{Effects of MLE on Met Uptake in HEK-293 Cells Overexpressing hOCT2}

Human embryonic kidney cells (HEK-293 cells) over-expressing hOCT2 were used to access the changes in Met uptake by MLE. HEK-293 cells over-expressing hOCT2 was obtained from ThermoFisher Scientific (Waltham, MA, USA). Dulbecco's modified Eagle's medium (DMEM) with $10 \% \mathrm{FBS}, 100 \mu \mathrm{g} / \mathrm{mL}$ of streptomycin, and $100 \mathrm{U} / \mathrm{mL}$ of penicillin was used for culture of the cell. The cell was humidified at $37^{\circ} \mathrm{C}$ with $5 \% \mathrm{CO}_{2}$ atmosphere.

Briefly, HEK-293 cells over-expressing hOCT2 were located into the poly-D-lysine coated 24-well plates $\left(5.0 \times 10^{5}\right.$ cells/well). DMEM with $10 \%$ fetal bovine serum was added into the plates and incubated for $24 \mathrm{~h}$. After the incubation, cells were washed twice using prewarmed Hank's balanced salt solution (HBSS). Prewarmed HBSS containing Met $(2.5 \mu \mathrm{M})$ with or without MLE (ranged from 0.1 to $100 \mu \mathrm{g} / \mathrm{mL}$ ) was added into the plates. For the positive control, metoprolol (MP, $25 \mu \mathrm{M})$ was used as the hOCT2 inhibitor. Plates were incubated for $10 \mathrm{~min}$ and cells were washed with iced blank HBSS. Then, the $150 \mu \mathrm{L}$ of $1 \mathrm{~N} \mathrm{NaOH}$ was added into the cell to lysis the cell. After 15 min of standing, $150 \mu \mathrm{L}$ of $1 \mathrm{~N} \mathrm{HCl}$ was added into the plates and cells was harvested. The lysates were centrifuged at $122,000 \times g \mathrm{rpm}$ for $10 \mathrm{~min}$. The concentration of Met was measured by LC-MS/MS.

\subsection{Hepatotoxicity of the Extended Intake of MLE}

To evaluate the hepatotoxicity of the extended intake of MLE, the serum biochemical parameters including alkaline phosphatase (ALP), alanine aminotransferase (ALT) were measured after the administration of MLE $(600 \mathrm{mg} / \mathrm{kg}$, oral) for 21 days. In brief, the rat was received the MLE $(600 \mathrm{mg} / \mathrm{mL}$, oral) or saline for 21 days. On day 0 and 21 days, the whole blood was collected via jugular vein and then stored at room temperature for $10 \mathrm{~min}$. Then, blood samples were centrifuged at $1000 \times g$ for $10 \mathrm{~min}$ and serum (supernatant) was separated. Serum biochemical parameters (ALP, alkaline phosphatase; ALT, alanine transaminase) were measured using a VetScan VS2 (Abaxis, Union city, CA, USA).

\subsection{HPLC and LC-MS/MS Analysis}

To extract the Met in plasma samples, the previously described method was partially validated using a rat plasma. In brief, aliquots $(0.1 \mathrm{~mL})$ of plasma were added to $10 \mu \mathrm{L}$ of $0.1 \mathrm{~N} \mathrm{HCl}$. Then, plasma was added into $50 \mu \mathrm{L}$ of IS ( $5 \mu \mathrm{g} / \mathrm{mL}$ in $\mathrm{MeOH})$. After adding $500 \mu \mathrm{L}$ of $\mathrm{ACN}$, they were shaken 
for $10 \mathrm{~min}$ and centrifuged at $10,000 \times g$ for $5 \mathrm{~min}$. Five hundred $\mu \mathrm{L}$ of the organic layer was transferred into a tube and dried at $40{ }^{\circ} \mathrm{C}$ under nitrogen stream. The residue was reconstituted in $50 \mu \mathrm{L}$ of mobile phase, vortexed, and an aliquot was injected onto the HPLC system.

The HPLC system (Shimadzu, Kyoto, Japan) with ultraviolet detector was used for the determination of Met in plasma. Chromatographic separation assay was performed using a Luna SCX analytical column $(150 \times 4.6-\mathrm{mm}$ inner diameter, $5-\mu \mathrm{m}$ particle size, Phenomenex, Torrance, CA, USA) maintained at $30^{\circ} \mathrm{C}$. The mobile phase consisted of ACN:ammonium phosphate monobasic $(10 \mathrm{mM})$ solution $(10: 90, v / v \%)$ adjusted to $\mathrm{pH} 4$ with orthophosphoric acid. Flow rate was $2 \mathrm{~mL} / \mathrm{min}$. For the UV detection of Met, the wavelength was set at $218 \mathrm{~nm}$.

For the Met uptake study in HEK-293 cells overexpressing hOCT2, LC-MS/MS system was used. The HPLC system (Agilent 1290 system, Agilent Technologies, Santa Clara, CA, USA) was used with an Agilent 6495 triple-quad mass spectrometer controlled by MassHunter software. Mass spectrometer was maintained with a gas temperature of $200{ }^{\circ} \mathrm{C}$, gas flow of $14 \mathrm{~L} / \mathrm{min}$, nebulizer pressure of $20 \mathrm{psi}$, capillary voltage of $3000 \mathrm{~V}$, and cell accelerator voltage of $5 \mathrm{~V}$. Positive multiple reaction-monitoring (MRM) was used to analyze Met using phenformin hydrochloride as an IS. For the separation of Met, a HILIC column (Kinetex HILIC, $4.6 \times 50 \mathrm{~mm}, 2.6 \mu \mathrm{m}$ ) was used and maintained at $30^{\circ} \mathrm{C}$. Mobile phases consisted of $10 \mathrm{mM}$ ammonium acetate in DW (pH 6.8):ACN $(15: 85, v / v \%)$ and the isocratic mode was used with a flow rate of $0.5 \mathrm{~mL} / \mathrm{min}$.

\subsection{Statistical Analysis}

All data were expressed as mean \pm standard error (S.E.) except the pharmacokinetic parameters. Statistical differences among groups were evaluated using a Student's $t$-test and performed by Graphpad prism (Graphpad Software, La Jolla, CA, USA).

\section{Results}

\subsection{Anti-Hyperglycemic Effect of Repeated Administrations of MLE}

DM induced rats were used in all period of experiments. After the injection of STZ, hyperglycemia was induced and homogeneously maintained (Figure 1). Animals with the blood glucose level above $200 \mathrm{mg} / \mathrm{dL}$ were used in this study.

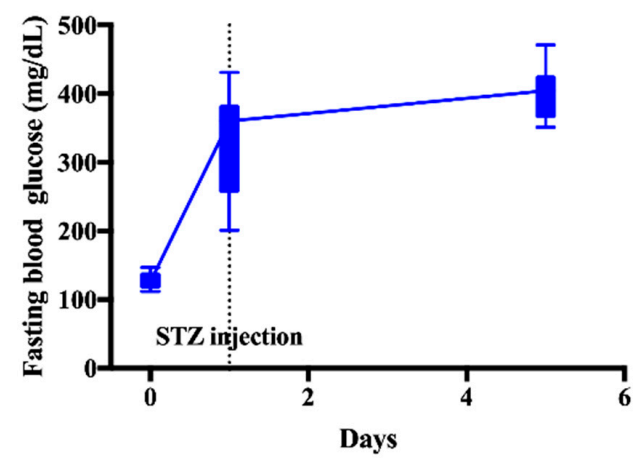

Figure 1. Fasting blood glucose levels after injection of streptozotocin (STZ) at a dose of $45 \mathrm{mg} / \mathrm{kg}$ in normal rats.

At 4, 9, 15, 18, and 21 day after administration of MLE, the relative blood glucose levels were significantly lowered as compared to those in saline treatment group (around 18, 42, 30, 17, and 37\% at $4,9,15,18$, and 21 days, respectively) (Figure 2). During all periods of the experiment, relative blood glucose levels in MLE group were lower than those in the saline group (Figure 2a). Calculated AUGs were illustrated in Figure $2 b$. After the repeated administration of MLE for 21 days, AUGs in MLE group were significantly decreased by $24 \%$ compared with those in the saline group (Figure $2 b$ ). 
(a)

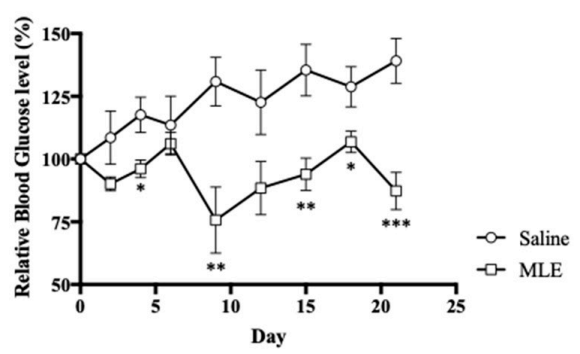

(b)

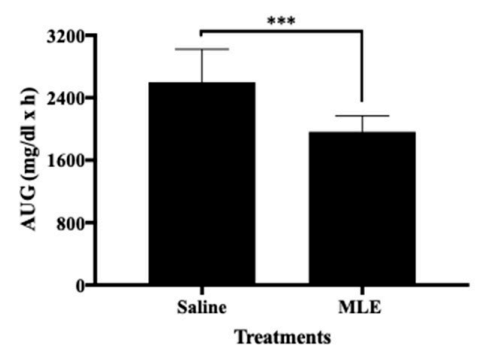

Figure 2. Relative blood glucose levels after oral administrations of Met (50 mg/kg) on day 22 in saline (circle) and MLE (square) treatments for 3 weeks (a), and AUG values of saline or MLE treatments for 3 weeks (b). ${ }^{*} p<0.05$. ${ }^{* *} p<0.01 .{ }^{* * *} p<0.001$.

\subsection{Impact of Repeated Administrations of MLE on the Anti-Hyperglycemic Effect of Various Doses of Met}

Time course of the relative blood glucose level after the oral administration of Met in the range $25-100 \mathrm{mg} / \mathrm{kg}$ in the saline or MLE treatment groups are illustrated in Figure 3. Anti-hyperglycemic effects of Met in the range $25-100 \mathrm{mg} / \mathrm{kg}$ showed a dose-dependent manner in either saline or MLE treatment groups (Figure 3a,b). In all experiment groups, the relative glucose level was decreased up to $4 \mathrm{~h}$ and maintained up to $12 \mathrm{~h}$ post-administration of Met. The mean relative glucose level values decreased to a maximum of $87.15 \pm 4.25 \%, 60.76 \pm 33.58 \%$, and $36.59 \pm 12.67 \%$ for 25,50 , and $100 \mathrm{mg} / \mathrm{kg}$ group, respectively, in the saline treatment group. In addition, these values decreased to a maximum of $66.99 \pm 7.77 \%, 49.97 \pm 22.44 \%$, and $24.95 \pm 4.33 \%$ for 25,50 , and $100 \mathrm{mg} / \mathrm{kg}$ group, respectively, in the MLE treatment group. AUG values after the administrations of different doses of Met $(25,50$, and $100 \mathrm{mg} / \mathrm{kg}$ ) are represented in Figure 3c. In two treatment groups (25 and $50 \mathrm{mg} / \mathrm{kg}$ ), AUG values of MLE groups were significantly higher than those of saline groups. When the MLE was treated for 3 weeks, the AUG values were decreased by 20, 25, and $16 \%$ for 25, 50, and $100 \mathrm{mg} / \mathrm{kg}$ treatment groups, respectively, if compared to the saline treatment group (Figure 3c). The slope of the MLE treatment group was increased to -5.20 if compared to that of the saline treatment group. It suggests that the repeated administrations of MLE potentiated the anti-hyperglycemic effect of Met.

(a)

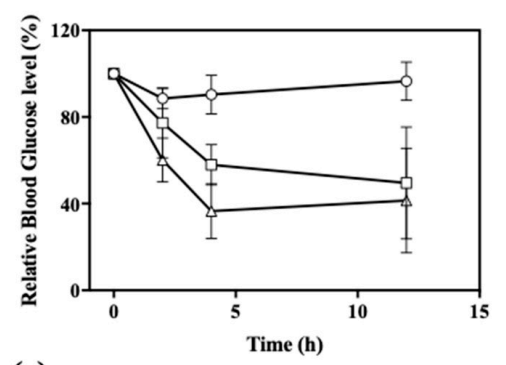

(c)

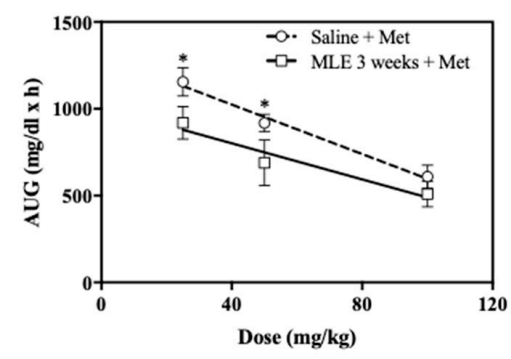

(b)

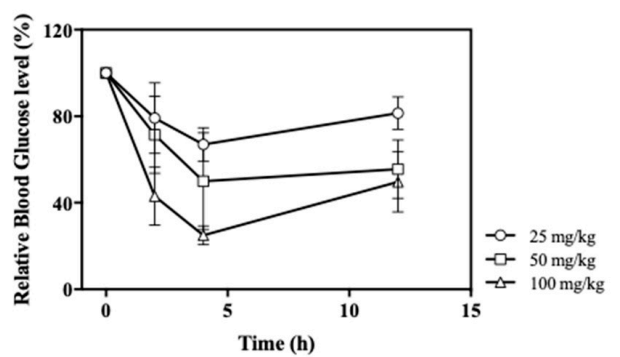

Figure 3. Relative blood glucose levels after oral administrations of Met (25,50, and $100 \mathrm{mg} / \mathrm{kg}$ ) on day 22 in saline (a) or MLE (b) treatments for 3 weeks, and AUG values of Met in saline (circle) and MLE (square) treatments for 3 weeks (c). ${ }^{*} p<0.05$. 


\subsection{Influence of Repeated Administrations of MLE to the Pharmacokinetics of Met}

To evaluate the influence of repeated administrations of MLE to the pharmacokinetics of Met, the pharmacokinetic profiles of Met were assessed in rats orally received the MLE or saline. Figure 4 shows the log plasma concentration-time curve of Met after administration of Met (50 mg/kg, PO) in saline and MLE groups, and the relevant pharmacokinetic parameters are listed in Table 1. Met in saline and MLE treated rats were detectable up to 12 and $24 \mathrm{~h}$, respectively. After administration of Met, the absorption of Met between groups showed a similar pattern with $\mathrm{T}_{\max }$ mean values of 1.7 and $1.9 \mathrm{~h}$, respectively. These results were supported by the previous study wherein reported the slow absorption ( $\mathrm{T}_{\max }$, range 1.5-2.0 h) of Met in DM rats [31]. The $\mathrm{T}_{1 / 2} \lambda \mathrm{z}$ was quite similar between the saline and MLE treatment group in the range of about 3-4 h. This is in line with previous studies in which the $T_{1 / 2} \lambda z$ was ranged from $3 \mathrm{~h}$ to $5 \mathrm{~h}$ [31,32]. Mean $\mathrm{AUC}_{0-24}$ in MLE group was 1.7-fold larger than that in the saline group. However, there was no significant difference between groups. This phenomenon might be relevant to individual variability. The $\mathrm{Cl} / \mathrm{F}$ in $\mathrm{MLE}$ group was significantly decreased by $50 \%$ compared to that in the saline group. This result indicates that the extended MLE treatment was reduced the elimination rate of Met.

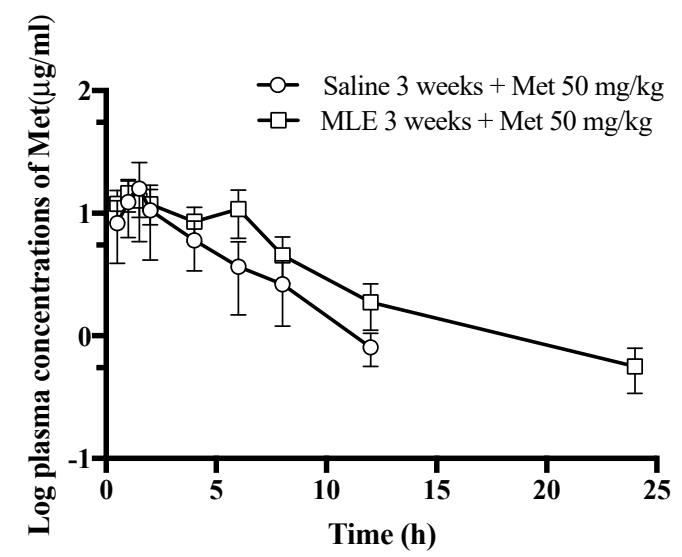

Figure 4. Plasma concentrations of Met after oral administrations of Met at a dose of $50 \mathrm{mg} / \mathrm{kg}$ in saline (circle) and MLE treatment groups (square).

Table 1. Pharmacokinetic parameters after oral administrations of Met at a dose of $50 \mathrm{mg} / \mathrm{kg}$ in MLE or saline treatment groups.

\begin{tabular}{cccc}
\hline Parameters & Unit & Saline 3 Weeks + Met & MLE 3 Weeks + Met \\
\hline $\mathrm{T}_{1 / 2} \lambda \mathrm{z}$ & $\mathrm{h}$ & $3.36 \pm 1.11$ & $4.4 \pm 1.27$ \\
$\mathrm{~T}_{\max }$ & $\mathrm{h}$ & $1.7 \pm 1.3$ & $1.9 \pm 2.3$ \\
$\mathrm{C}_{\max }$ & $\mu \mathrm{g} / \mathrm{mL}$ & $10.85 \pm 9.66$ & $12.17 \pm 1.06$ \\
$\mathrm{AUC}_{0-24}$ & $\mathrm{~h} \mu \mathrm{g} / \mathrm{mL}$ & $42.74 \pm 33.29$ & $73.75 \pm 15.23$ \\
$\mathrm{~V} / \mathrm{F}$ & $\mathrm{mL} / \mathrm{kg}$ & $6324.98 \pm 2915.05$ & $4143.72 \pm 1291.5$ \\
$\mathrm{Cl} / \mathrm{F}$ & $\mathrm{mL} / \mathrm{h} / \mathrm{kg}$ & $1381.29 \pm 545.57$ & $657.74 \pm 150.25^{* *}$ \\
\hline
\end{tabular}

$\mathrm{T}_{1 / 2} \lambda z$, half-life of the terminal portion of the curve; $\mathrm{T}_{\max }$, time at the maximum drug concentration; $\mathrm{C}_{\max }$, maximum plasma drug concentration; $\mathrm{AUC}_{0-24}$, area under the curve from 0 to the last; $\mathrm{V} / \mathrm{F}$, volume of distribution during the elimination phase; $\mathrm{Cl} / \mathrm{F}$, body clearance during the elimination phase. ${ }^{* *} p<0.01$.

\subsection{Interference of MLE to Met Analysis in Rat Plasma}

Before the pharmacokinetic analysis of Met, the influence of MLE to Met analysis in rat plasma was evaluated by adding the MLE to the Met spiking plasma. Accuracy (RE) and precision (RSD) values of inter- and intra-day were listed in Table 2. The intra-day RSD and RE were 9.29\% and 7.65\% for LQC, $8.47 \%$ and $8.48 \%$ for MQC, and 3.01\% and $2.17 \%$ for HQC, respectively. The inter-day RSD and RE were $7.17 \%$ and $9.87 \%$ for LQC, $9.60 \%$ and $8.91 \%$ for MQC, and $5.03 \%$ and $3.77 \%$ for HQC, respectively. When the rat plasma with MLE $(10 \mu \mathrm{g} / \mathrm{mL})$ was used for the spiking of Met, the intra-day 
RE and RSD were $9.20 \%$ and $9.63 \%$ for LQC, $8.11 \%$ and $7.82 \%$ for MQC, and $2.49 \%$ and $2.03 \%$ for HQC, respectively. The inter-batch RSD and RE of all QC samples in MLE spiked plasma were ranged from $4.13 \%$ to $8.72 \%$, and from $3.14 \%$ to $8.62 \%$, respectively. These data were within the acceptance criterion recommended by US Food and Drug Administration [33]. In addition, after the exposure of MLE for 21 days, there is no detectable peak at the retention time of Met (Figure 5). It suggests that the MLE in rat plasma did not affect the Met analysis.

Table 2. Intra- and inter-day accuracy and precision of Met in rat plasma spiked with MLE.

\begin{tabular}{cccccc}
\hline \multirow{2}{*}{ Condition } & \multirow{2}{*}{ QC } & \multicolumn{2}{c}{ Intra-Day $(\boldsymbol{n}=\mathbf{6})$} & \multicolumn{2}{c}{ Inter-Day $(\boldsymbol{n}=\mathbf{5})$} \\
\cline { 3 - 6 } & & RSD\% & RE\% & RSD\% & RE\% \\
\hline \multirow{2}{*}{ Met in rat } & LQC & 9.29 & 7.65 & 7.17 & 9.87 \\
plasma & MQC & 8.47 & 8.48 & 9.6 & 8.91 \\
& HQC & 3.01 & 2.17 & 5.03 & 3.77 \\
\hline Met in rat & LQC & 9.2 & 9.63 & 6.35 & 6.01 \\
plasma spiked & MQC & 8.11 & 7.82 & 8.72 & 8.62 \\
with MLE & HQC & 2.49 & 2.03 & 4.13 & 3.14 \\
\hline
\end{tabular}

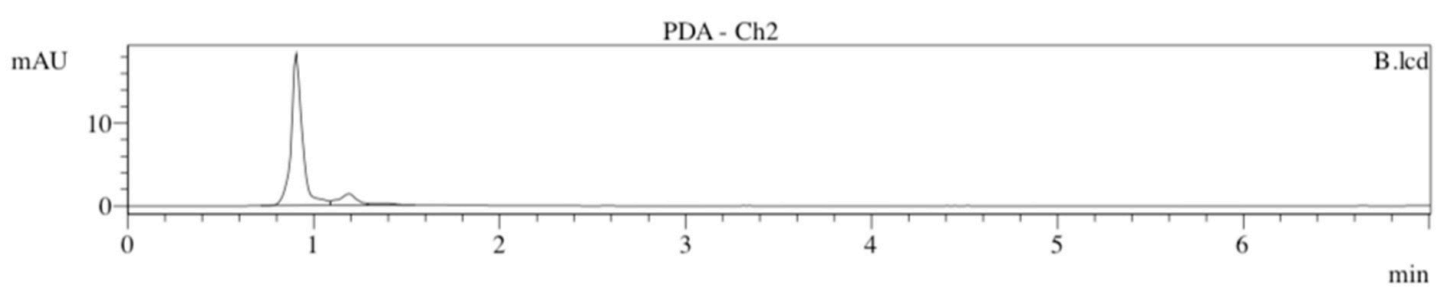

Figure 5. Chromatogram of blank plasma sample after the extended intake of MLE.

\subsection{Effects of MLE on Met Uptake in HEK-293 Cells Overexpressing hOCT2}

After the repeated administrations of MLE, the elimination rate of Met was lowered compared to the saline group. It has been reported that Met was predominantly transported to the kidney via hOCT2 for the elimination [34]. Thus, we postulated that the lowered elimination of Met is caused by the hOCT2 inhibition via the extended intake of MLE. Herein, the effect of MLE on Met uptake was evaluated in HEK-293 cell overexpressing hOCT2. Figure 6 was illustrated the change in Met uptake via hOCT2 by the various concentrations of MLE. MP, a well-known hOCT2 inhibitor, was significantly reduced Met uptake if compared to that of control. Dose-dependent inhibition of Met uptake was shown by increasing the concentration of MLE. Treatments of MLE at 1, 10 and $100 \mu \mathrm{g} / \mathrm{mL}$ were significantly decreased Met uptake to 36\%, 68\%, and 76\%, respectively. In the MLE treatment group at $0.1 \mu \mathrm{g} / \mathrm{mL}$, the Met uptake was similar to that of the control group. This result indicates that the MLE reduced the Met uptake via hOCT2 inhibition with the MLE concentration-dependent manner.

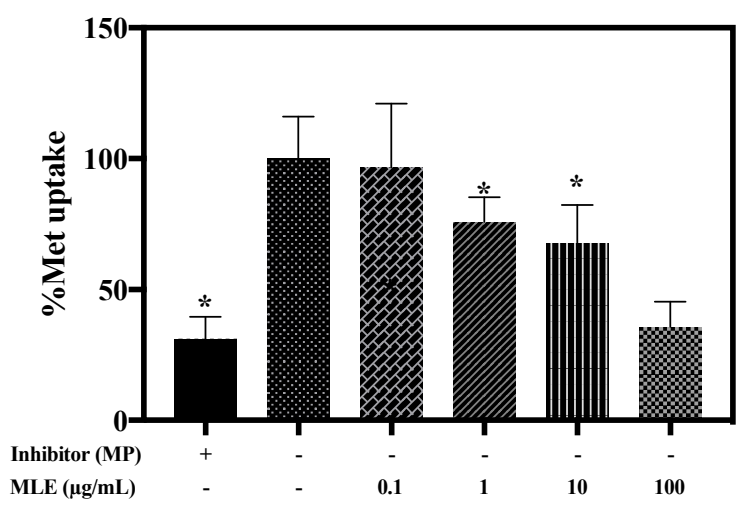

Figure 6. Met uptake with or without MLE in HEK-293 cells overexpressing hOCT2. ${ }^{*} p<0.05$. 


\subsection{Hepatotoxicity of the Extended Intake of MLE}

Serum biochemical parameters including alkaline phosphatase (ALP), alanine aminotransferase (ALT) were evaluated and listed in Table 3. There is no significant difference between ALP and ALT for control and MLE treated group. According to Han et al. (2010) [35], ALP and ALT values in normal SD rats were ranged from 91 to $250 \mathrm{U} / \mathrm{L}$ and from 26 to $101 \mathrm{U} / \mathrm{L}$, respectively. It suggests that the dosage used in this study did not produce a negative impact on the liver.

Table 3. Serum biochemistry parameters in female and male rats treated with MLE.

\begin{tabular}{cccc}
\hline \multirow{2}{*}{ Parameters } & \multirow{2}{*}{ Units } & \multicolumn{2}{c}{ Groups } \\
\cline { 3 - 4 } & & Control Group & MLE Group \\
\hline ALP & U/L & $142.5 \pm 10.2$ & $145.3 \pm 20.8$ \\
ALT & U/L & $40.4 \pm 10.3$ & $42.0 \pm 9.5$ \\
\hline
\end{tabular}

ALP, alkaline phosphatase; ALT, alanine aminotransferase.

\section{Discussion}

Evaluation of drug interactions is essential to applications of drugs and herbal medicines in clinical situations. In general, herbal medicine or health supplements are taken long-term. Thus, the extended influence of MLE to Met was evaluated in terms of pharmacokinetics and pharmacodynamics. This is the first study to evaluate the extended influence of MLE to Met.

In the present study, the extended intake of MLE (3 weeks) lowered the blood glucose level in DM-induced rats. This result is similar with previous literatures reported that the blood glucose lowering effects of the mulberry, leaf, and fruit extract [1,6-11,13,36-39]. These effects could be due to the presence of trans-caffeic acid, syringaldehyde, and chlorogenic acid in mulberry $[11,13,40]$. In particular, chlorogenic acid suppresses hepatic gluconeogenesis via both the inhibition of glucose-6-phosphatase (G6Pase) activity and the activation of AMP-dependent kinase (AMPK) [11,12]. In addition, it is reported that the trans-caffeic acid has ability to increase glucose uptake in muscle and GLUT-4 expression in skeletal muscles [30]. MLE used in this study includes the trans-caffeic acid, syringaldehyde and chlorogenic acid, thus results in this study were also supported by the previous investigations reported the anti-hyperglycemic effect of trans-caffeic acid, rutin, and chlorogenic acid in DM rats [11,12].

The extended intake of MLE ( 3 weeks) was associated with a $24 \%$ increased anti-hyperglycemic effect if compared with the saline treatment group. When the MLE was administered for 3 weeks, the anti-hyperglycemic effect of Met was enhanced in all doses of Met. Met treatment with MLE intake led to an enhanced increase in the anti-hyperglycemic effect. This increase indicates that the extended intake of MLE enhanced the anti-hyperglycemic effect of Met. Enhanced anti-hyperglycemic effect of Met by MLE was shown in all doses of Met, except the high dose of Met $(100 \mathrm{mg} / \mathrm{kg})$. This phenomenon might be due to the saturation of Met by the overdose [41]. In humans, the therapeutic dose of Met is $850 \mathrm{mg}$, corresponding to a dose of $\sim 85 \mathrm{mg} / \mathrm{kg}$ in rats. Thus, a high dose of Met $(100 \mathrm{mg} / \mathrm{kg})$ in this study could result in the maximum anti-hyperglycemic effect of Met.

This enhanced effect could not be explained by only the individual anti-hyperglycemic effect of MLE. Interactions between herbal extract and anti-hyperglycemic drug have been reported to affect either efficacy or pharmacokinetics of the drug [20-22]. For instance, Aloe vera and Andrographis paniculata showed the inhibitory effects on CYP3A4 resulting in the increased efficacy of anti-hyperglycemic drugs such as pioglitazone, repaglinide, and glimepiride [28,42]. In opposition to this, St John's Wort and Ginseng stimulated the induction of CYP3A4 resulting in the decreased efficacy of anti-hyperglycemic drugs, such as glibenclamide and pioglitazone [21,27]. Thus, we speculated that the extended MLE intake might alter the pharmacokinetic property of Met.

The bioanalytical method for Met was partially validated in the presence or absence of MLE in rat plasma. Whether the MLE was added or not in rat plasma, the inter- and intra-batch precision and accuracy of Met were estimated below 15\%, which is the acceptance criteria recommended by US Food 
and Drug Administration [33]. It suggests that the presence of MLE in rat plasma did not impact on the bioanalytical method of Met.

Herein, the extended intake of MLE lowered the $\mathrm{Cl} / \mathrm{F}$ of Met. This extended Met elimination phase suggests that the extended MLE intake altered the pharmacokinetics of Met in DM-induced rats. This pharmacokinetic feature could be explained by a hypothesis. It is demonstrated that Met relies on facilitated transport by transporters for delivery to the organs or tissues [43]. In particular, OCTs, including OCT1 and OCT2, and multidrug and toxin extrusion proteins (MATEs), which function as transporters of metabolic and xenobiotic organic cations, are known as determinants of Met response [43]. Met is delivered to the kidney by OCT2 and excreted in urine by MATEs. In this study, MLE was inhibited the hOCT2 in a concentration-dependent manner. When the MLE at $100 \mu \mathrm{g} / \mathrm{mL}$ was treated to the HEK-293 cells overexpressing the hOCT2, hOCT2 inhibition of MLE was similar to that of MPP, a hOCT2 inhibitor. These results suggest that the MLE intake could lower the elimination rate of Met by reducing the uptake of Met to the kidney. However, the levels/expression of the hOCT2 and MATEs in vivo system should be evaluated to clarify the result. Several cases of interactions between Met and herbal medicines have been reported that focus on the impact on transporters [23,44]. According to You et al. (2018), Houttuynia cordata ethanol extract reduced the rat OCT2-mediated renal excretion of Met and increased systemic exposure of Met. Also, there is another hypothesis. Met is metabolized by hepatic CYP2C11,2D1, and 3A1/2, and eliminated via the kidneys in rats [30]. In studies, plant extracts of caffeic acid and chlorogenic acid could inhibit the activities of CYP2C11 and CYP3A1 [45,46]. Slowed elimination pattern of Met through the extended MLE intake might be explained by the decreasing hepatic metabolism of Met via inhibition of hepatic enzymes. However, further interaction studies between MLE and transporters are needed to clarify this issue.

\section{Conclusions}

This study is the first published report of the pharmacokinetic alternation of Met through 3 week-intake of MLE. MLE intake for 3 weeks produced an anti-hyperglycemic effect. Orally administered Met after the MLE intake for 3 weeks enhanced the anti-hyperglycemic effect of Met compared to Met alone. This enhanced effect of Met might be due to the increase of systemic exposure of Met. In addition, extended MLE intake altered the pharmacokinetic properties of Met via the reduction of Met uptake to kidney by inhibiting the hOCT2. Therefore, the extended MLE intake with Met could reduce the unwanted side effects of Met by decreasing the dose of Met.

Author Contributions: Conceptualization, H.W.H. and Y.-G.N.; Methodology, H.W.H.; Software, K.-H.B.; Validation, S.-J.K.; Formal analysis, M.K.; Resources, K.-T.K. and J.-S.K.; Data curation, Y.-H.K.; Writing-original draft preparation, H.-K.L.; Writing-review and editing, C.-W.C.; Visualization, J.-S.B.; Supervision, C.-W.C. All authors have read and agreed to the published version of the manuscript.

Funding: This work was supported by Korea Institute of Planning and Evaluation for Technology in Food, Agriculture, Forestry and Fisheries (IPET) through (Agri-Bioindustry Technology Development Program), funded by Ministry of Agriculture, Food and Rural Affairs (MAFRA) (no. 315024-3).

Conflicts of Interest: The authors declare no conflict of interest.

\section{References}

1. Marniemi, J.; Parkki, M.G. Radiochemical assay of glutathione S-epoxide transferase and its enhancement by phenobarbital in rat liver in vivo. Biochem. Pharmacol. 1975, 24, 1569-1572. [CrossRef]

2. Amos, A.F.; McCarty, D.J.; Zimmet, P. The rising global burden of diabetes and its complications: Estimates and projections to the year 2010. Diabet. Med. 1997, 14 (Suppl. 5), S1-S85. [CrossRef]

3. Lin, Y.; Sun, Z. Current views on type 2 diabetes. J. Endocrinol. 2009, 204, 1-11. [CrossRef] [PubMed]

4. Cheng, A.Y.Y. Oral antihyperglycemic therapy for type 2 diabetes mellitus. Can. Med. Assoc. J. 2005, 172, 213-226. [CrossRef] [PubMed]

5. Brunton, L.; Knollman, B.; Hilal-Dandan, R. Goodman and Gilman's The Pharmacological Basis of Therapeutics, 13th ed.; McGraw Hill Professional: New York, NY, USA, 2017. 
6. Ren, C.; Zhang, Y.; Cui, W.; Lu, G.; Wang, Y.; Gao, H.; Huang, L.; Mu, Z. A polysaccharide extract of mulberry leaf ameliorates hepatic glucose metabolism and insulin signaling in rats with type 2 diabetes induced by high fat-diet and streptozotocin. Int. J. Biol. Macromol. 2015, 72, 951-959. [CrossRef] [PubMed]

7. Zhang, Y.; Ren, C.; Lu, G.; Mu, Z.; Cui, W.; Gao, H.; Wang, Y. Anti-hyperglycemic effect of mulberry leaf polysaccharide by inhibiting pancreatic islet cell apoptosis and ameliorating insulin secretory capacity in diabetic rats. Int. Immunopharmacol. 2014, 22, 248-257. [CrossRef]

8. Ştefănuţ, M.N.; Căta, A.; Pop, R.; Tănasie, C.; Boc, D.; Ienaşcu, I.; Ordodi, V. Anti-hyperglycemic effect of bilberry, blackberry and mulberry ultrasonic extracts on diabetic rats. Plant Foods Hum. Nutr. 2013, 68, 378-384. [CrossRef]

9. Wang, Y.; Xiang, L.; Wang, C.; Tang, C.; He, X. Antidiabetic and antioxidant effects and phytochemicals of mulberry fruit (morus alba L.) polyphenol enhanced extract. PLoS ONE 2013, 8, e71144. [CrossRef]

10. Jeszka-Skowron, M.; Flaczyk, E.; Jeszka, J.; Krejpcio, Z.; Król, E.; Buchowski, M.S. Mulberry leaf extract intake reduces hyperglycaemia in streptozotocin (STZ)-induced diabetic rats fed high-fat diet. J. Funct. Foods 2014, 8, 9-17. [CrossRef]

11. Ong, K.W.; Hsu, A.; Tan, B.K.H. Anti-hyperglycemic and anti-lipidemic effects of chlorogenic acid are mediated by AMPK activation. Biochem. Pharmacol. 2013, 85, 1341-1351. [CrossRef]

12. Ong, K.W.; Hsu, A.; Tan, B.K.H. Chlorogenic acid stimulates glucose transport in skeletal muscle via AMPK activation: A contributor to the beneficial effects of coffee on diabetes. PLoS ONE 2012, 7, e32718. [CrossRef] [PubMed]

13. Hunyadi, A.; Martins, A.; Hsieh, T.-J.; Seres, A.; Zupkó, I. Chlorogenic acid and rutin play a major role in the in vivo anti-hyperglycemic activity of Morus alba leaf extract on type II diabetic rats. PLoS ONE 2012, 7, e50619. [CrossRef] [PubMed]

14. Jung, U.J. Antihyperglycemic and antioxidant properties of caffeic acid in $d b / d b$ Mice. J. Pharmacol. Exp. Ther. 2006, 318, 476-483. [CrossRef] [PubMed]

15. Hsu, F.L.; Chen, Y.C.; Cheng, J.T. Caffeic acid as active principle from the fruit of Xanthium strumarium to lower plasma glucose in diabetic rats. Planta Med. 2000, 66, 228-230. [CrossRef]

16. Oboh, G.; Agunloye, O.M.; Adefegha, S.A.; Akinyemi, A.J.; Ademiluyi, A.O. Caffeic and chlorogenic acids inhibit key enzymes linked to type 2 diabetes (in vitro): A comparative study. J. Basic Clin. Physiol. Pharmacol. 2015, 26, 1-6. [CrossRef]

17. Huang, D.-W.; Shen, S.-C.; Wu, J.S.-B. Effects of Caffeic Acid and Cinnamic Acid on Glucose Uptake in Insulin-Resistant Mouse Hepatocytes. J. Agric. Food Chem. 2009, 57, 7687-7692. [CrossRef]

18. Prabhakar, P.K.; Kumar, A.; Doble, M. Combination therapy: A new strategy to manage diabetes and its complications. Phytomedicine 2014, 21, 123-130. [CrossRef]

19. Prabhakar, P.K.; Doble, M. Effect of natural products on commercial oral antidiabetic drugs in enhancing 2-deoxyglucose uptake by 3T3-L1 adipocytes. Ther. Adv. Endocrinol. 2011, 2, 103-114. [CrossRef]

20. Amin, M.; Suksomboon, N. Pharmacotherapy of type 2 diabetes mellitus: An update on drug-drug interactions. Drug Saf. 2014, 37, 903-919. [CrossRef]

21. May, M.; Schindler, C. Clinically and pharmacologically relevant interactions of antidiabetic drugs. Ther. Adv. Endocrinol. 2016, 7, 69-83. [CrossRef]

22. Ríos, J.L.; Francini, F.; Schinella, G.R. Natural products for the treatment of type 2 diabetes mellitus. Planta Med. 2015, 81, 975-994. [CrossRef] [PubMed]

23. You, B.H.; Chin, Y.W.; Kim, H.; Choi, H.S.; Choi, Y.H. Houttuynia cordata extract increased systemic exposure and liver concentrations of metformin through OCTs and MATEs in rats. Phytother. Res. 2018, 32, 1004-1013. [CrossRef] [PubMed]

24. Brown, L.; Heyneke, O.; Brown, D.; van Wyk, J.P.H.; Hamman, J.H. Impact of traditional medicinal plant extracts on antiretroviral drug absorption. J. Ethnopharmacol. 2008, 119, 588-592. [CrossRef] [PubMed]

25. Nabekura, T.; Kamiyama, S.; Kitagawa, S. Effects of dietary chemopreventive phytochemicals on P-glycoprotein function. Biochem. Biophys. Res. Commun. 2005, 327, 866-870. [CrossRef] [PubMed]

26. Juan, H.; Terhaag, B.; Cong, Z.; Bi-Kui, Z.; Rong-Hua, Z.; Feng, W.; Fen-Li, S.; Juan, S.; Jing, T.; Wen-Xing, P. Unexpected effect of concomitantly administered curcumin on the pharmacokinetics of talinolol in healthy Chinese volunteers. Eur. J. Clin. Pharmacol. 2007, 63, 663-668. [CrossRef] [PubMed]

27. Mills, E.; Montori, V.M.; Wu, P.; Gallicano, K.; Clarke, M.; Guyatt, G. Interaction of St John's wort with conventional drugs: Systematic review of clinical trials. BMJ 2004, 329, 27-30. [CrossRef] 
28. Rehman, S.U.; Choi, M.S.; Choe, K.; Yoo, H.H. Interactions between herbs and antidiabetics: An overview of the mechanisms, evidence, importance, and management. Arch. Pharm. Res. 2015, 38, 1281-1298. [CrossRef]

29. Son, G.-H.; Lee, H.-J.; Na, Y.-G.; Lee, H.-K.; Kim, S.-J.; Huh, H.-W.; Kim, K.-T.; Kang, J.-S.; Kim, Y.-H.; Myung, C.-S.; et al. Formulation and statistical analysis of an herbal medicine tablet containing Morus alba leaf extracts. J. Pharm. Investig. 2018, 49, 625-634. [CrossRef]

30. Jung, S.-H.; Han, J.-H.; Park, H.-S.; Lee, D.-H.; Kim, S.J.; Cho, H.S.; Kang, J.S.; Myung, C.-S. Effects of unaltered and bioconverted mulberry leaf extracts on cellular glucose uptake and antidiabetic action in animals. BMC Complement. Altern. Med. 2019, 19, 55. [CrossRef]

31. Choi, Y.H.; Lee, D.C.; Lee, I.; Lee, M.G. Changes in metformin pharmacokinetics after intravenous and oral administration to rats with short-term and extended diabetes induced by streptozotocin. J. Pharm. Sci. 2008, 97, 5363-5375. [CrossRef]

32. Choi, Y.H.; Kim, S.G.; Lee, M.G. Dose-independent pharmacokinetics of metformin in rats: Hepatic and gastrointestinal first-pass effects. J. Pharm. Sci. 2006, 95, 2543-2552. [CrossRef] [PubMed]

33. U.S. Department of Health and Human Services; FDA. Bioanalytical Method Validation, Guidance for Industry. 2001. Available online: https:/www.fda.gov/files/drugs/published/Bioanalytical-MethodValidation-Guidance-for-Industry.pdf (accessed on 30 May 2018).

34. Gong, L.; Goswami, S.; Giacomini, K.M.; Altman, R.B.; Klein, T.E. Metformin pathways: Pharmacokinetics and pharmacodynamics. Pharmacogenet. Genom. 2012, 22, 820-827. [CrossRef] [PubMed]

35. Han, Z.Z.; Xu, H.D.; Kim, K.H.; Ahn, T.H.; Bae, J.S.; Lee, J.Y.; Woo, S.J.; Yoo, H.J.; Lee, H.K.; Kim, K.H.; et al. Reference data of the main physiological parameters in control Sprague-Dawley rats from pre-clinical toxicity studies. Lab. Anim. Res. 2010, 26, 153-164. [CrossRef]

36. Andallu, B.; Suryakantham, V.; Srikanthi, B.L.; Reddy, G.K. Effect of mulberry (Morus indica L.) therapy on plasma and erythrocyte membrane lipids in patients with type 2 diabetes. Clin. Chim. Acta 2001, 314, 47-53. [CrossRef]

37. Park, M.-Y.; Lee, K.-S.; Sung, M.-K. Effects of dietary mulberry, Korean red ginseng, and banaba on glucose homeostasis in relation to PPAR- $\alpha$, PPAR- $\gamma$, and LPL mRNA expressions. Life Sci. 2005, 77, 3344-3354. [CrossRef] [PubMed]

38. Andallu, B.; Varadacharyulu, N.C. Gluconeogenic substrates and hepatic gluconeogenic enzymes in streptozotocin-diabetic rats: Effect of mulberry (Morus indica L.) Leaves. J. Med. Food 2007, 10, 41-48. [CrossRef]

39. Miyahara, C.; Miyazawa, M.; Satoh, S.; Sakai, A.; Mizusaki, S. Inhibitory effects of mulberry leaf extract on postprandial hyperglycemia in normal rats. J. Nutr. Sci. Vitaminol. 2004, 50, 161-164. [CrossRef]

40. Santana-Gálvez, J.; Cisneros-Zevallos, L.; Jacobo-Velázquez, D.A. Chlorogenic acid: Recent advances on its dual role as a food additive and a nutraceutical against metabolic syndrome. Molecules 2017, 22, 358. [CrossRef]

41. Kanto, K.; Ito, H.; Noso, S.; Babaya, N.; Hiromine, Y.; Taketomo, Y.; Toma, J.; Niwano, F.; Yasutake, S.; Kawabata, Y.; et al. Effects of dosage and dosing frequency on the efficacy and safety of high-dose metformin in Japanese patients with type 2 diabetes mellitus. J. Diabetes. Investig. 2018, 9, 587-593. [CrossRef]

42. Holstein, A.; Beil, W.; Kovacs, P. CYP2C metabolism of oral antidiabetic drugs-impact on pharmacokinetics, drug interactions and pharmacogenetic aspects. Expert Opin. Drug Metab. Toxicol. 2012, 8, 1549-1563. [CrossRef]

43. Shu, Y.; Sheardown, S.A.; Brown, C.; Owen, R.P.; Zhang, S.; Castro, R.A.; Ianculescu, A.G.; Yue, L.; Lo, J.C.; Burchard, E.G.; et al. Effect of genetic variation in the organic cation transporter 1 (OCT1) on metformin action. J. Clin. Investig. 2007, 117, 1422-1431. [CrossRef] [PubMed]

44. Kudolo, G.B.; Wang, W.; Javors, M.; Blodgett, J. The effect of the ingestion of Ginkgo biloba extract (EGb 761) on the pharmacokinetics of metformin in non-diabetic and type 2 diabetic subjects-A double blind placebo-controlled, crossover study. Clin. Nutr. 2006, 25, 606-616. [CrossRef] [PubMed]

45. Geng, T.; Si, H.; Kang, D.; Li, Y.; Huang, W.; Ding, G.; Wang, Z.; Bi, Y.; Zhang, H.; Xiao, W. Influences of Re Du Ning Injection, a traditional Chinese medicine injection, on the CYP450 activities in rats using a cocktail method. J. Ethnopharmacol. 2015, 174, 426-436. [CrossRef] [PubMed]

46. Xu, X.; Geng, T.; Zhang, S.; Kang, D.; Li, Y.; Herbal, G.D.C. Inhibition of Re Du Ning Injection on enzyme activities of rat liver microsomes using cocktail method. Chin. Herb. Med. 2016, 8, 231-241. [CrossRef]

(C) 2020 by the authors. Licensee MDPI, Basel, Switzerland. This article is an open access article distributed under the terms and conditions of the Creative Commons Attribution (CC BY) license (http://creativecommons.org/licenses/by/4.0/). 